\title{
Comunicação pública: mais para teoria do que para prática
}

Mônica Prado'

\section{Resumo}

Práticas de Comunicação Pública em Brasília é o nome da coletânea@ pública que reúne trabalhos de sete jornalistas. Os artigos são o resultado de pesquisas acadêmicas sobre como anda o exercício do jornalismo público na televisão e a prática de assessoria em comunicação pública em Brasília. Os artigos abordam o jornalismo público em TVs abertas e na TV Brasil, as práticas de comunicação das agências reguladoras federais, de órgãos do Poder Executivo do Distrito Federal e dos Tribunais Superiores em Brasília. O estudo sobre campanhas educativas: a face pública da publicidade conta com a colaboração do estudante do $4^{\circ}$ semestre de Publicidade e Propaganda, Marcelo Ribeiro. A organização do livro Práticas de Comunicação Pública é da jornalista e mestre em Comunicação, Mônica Prado, e os artigos são das jornalistas: Aurilene Moura, Basilia Rodrigues, Lívia Almeida, Lívia Davanzo, Vânia Ferreira e Tatiany Tonelini.

Palavras-chave: Comunicação pública. Cidadania. Campanhas educativas.

Práticas de Comunicação Pública em Brasília consolida a produção acadêmica sobre comunicação pública, jornalismo público e publicidade de utilidade pública realizada pelo Grupo de Pesquisa - Educação Superior e Comunicação do Centro Universitário de Brasília (UniCEUB). O objetivo é registrar a memória do que se está fazendo nos dois últimos anos. O relato dos resultados das pesquisas e o lançamento do livro fizeram parte das atividades do VI Congresso de Ensino, Pesquisa e Extensão e VI Encontro de Iniciação Científica, realizado em outubro de 2008, no campus do UniCEUB.

1 Jornalista, mestre em Comunicação pela Universidade de Brasília (UnB), docente e pesquisadora do Grupo de Pesquisa - Educação Superior e Comunicação, do UniCEUB. 
A linha transversal que perpassa todos os artigos é a de que a comunicação pública praticada em Brasília está muito mais para a teoria do que para a prática. O marco conceitual de todos os trabalhos é um tripé que entende que o lócus de comunicação pública é o espaço entre Estado, sociedade e cidadão, que a comunicação pública está calcada no direito à informação, e que o efeito da prática de comunicação pública é a participação das decisões públicas. Considerando o lócus de atuação, o conteúdo das mensagens e o efeito desejado, os emissores da comunicação pública estão presentes nos três setores sociais: primeiro setor (governo), segundo setor (mercado), terceiro setor (sociedade civil). O universo da comunicação pública/ de utilidade pública/de interesse público enfatiza o papel relacional da comunicação, o papel central do cidadão e o papel de compromisso na busca de resultados tangíveis para o desenvolvimento social.

O artigo da jornalista Aurilene Moura mostra que, no Brasil, o conceito vem sendo discutido por estudiosos em que se destacam: Elizabeth Brandão, Heloíza Matos, Jorge Duarte e Luis Martins. Os acadêmicos brasileiros tomaram como ponto de partida os conceitos formulados por Pierre Zémor, presidente fundador da Association des Responsables de Communication des Institutions Publiques Communication Publique ${ }^{2}$.

No artigo, Aurilene indica que os brasileiros compartilharam conhecimento, informação e opinião com Zémor. Também aponta que entre os autores há uma autorreferência e uma referência cruzada dos conceitos de Comunicação Pública. A jornalista destaca a ausência de discussões entre os autores sobre práticas e sobre os efeitos de comunicação pública, no sentido de buscar saber como se processa a participação ativa do cidadão na construção das políticas públicas que o envolvem.

Basília Rodrigues, também graduada em Jornalismo, aborda em seu artigo as práticas de comunicação dos tribunais superiores em Brasília, pesquisa inserida no Programa de Iniciação Científica do UniCEUB, de 2007. De novembro de 2007 a março de 2008, sete tribunais e órgãos públicos foram visitados: STM (Superior Tribunal Militar), STJ (Superior Tribunal de Justiça), TSE (Tribunal Superior Eleitoral), TST (Tribunal Superior do Trabalho), TCU (Tribunal de Conta da União), MPF (Ministério Público Federal) e CNJ (Conselho Nacional de Justiça).

2 O trabalho e a produção da Associação estão em: http://www.communication-publique.fr. 
O Supremo Tribunal Federal (STF), inicialmente previsto no escopo da pesquisa, tendo em vista o difícil acesso e a pouca disponibilidade apresentada por seus gestores, não foi pesquisado. O TCU, o MPF e o CNJ foram incluídos, apesar de não serem tribunais superiores, porque o documento dos Encontros de Assessores de Comunicação do Judiciário (Cartas dos Encontros) tratou de apontá-los como integrantes da rede de comunicadores públicos de órgãos ligados à Justiça.

As Cartas enfatizam quanto à política de comunicação: (i) profissionalização e qualificação das assessorias; (ii) estruturação das assessorias dentro de cada órgão; (iii) o direito do cidadão à informação; (iv) democratização e transparência da informação; (v) Justiça a serviço da cidadania; (vi) informação como bem público e comunicação pautada no interesse público e na inclusão social; e (vii) consolidação da rede de comunicadores públicos do Poder Judiciário, do Ministério Público e de áreas ligadas à Justiça.

Na pesquisa de campo foram identificadas às práticas de Jornalismo, de Comunicação Interna, de Publicidade, de Campanhas Promocionais e de Interação com o cidadão. Os gestores de comunicação estão preocupados em fazer cumprir o indicado como política pelas Cartas dos Encontros: construir, aperfeiçoar e/ou firmar perfil de comunicação voltado para a cidadania, ou seja, comunicação, cuja premissa é o direito à informação como bem público. Basilia conclui a pesquisa, apontando que, na prática, há diversos níveis de operacionalização, e que a comunicação praticada pelos órgãos pesquisados pode ser classificada em reativa e pró-ativa.

A pesquisa realizada em 2006, por alunos de Comunicação Organizacional ${ }^{3}$ sobre as práticas de comunicação pública nas agências reguladoras federais sediadas em Brasília-DF, aponta também que há desníveis entre as agências e que não há norte comum sobre direito à informação. Diante dos resultados, é possível

\footnotetext{
${ }^{3}$ Amanda e Danielle Lopes - Pesquisa documental sobre agências reguladoras; Antônio Martins, Andrea Lopes, Daniela Torres e Nara Regina - Entrevista em profundidade com jornalistas e editores de veículos especializados em Economia que cobrem Agências Reguladoras; Carolina Santos e Verônica Soares - Agência Nacional de Vigilância Sanitária (ANVISA); Daniela Lima - Agência Nacional de Águas (ANA); Elaine Carneiro - Agência Nacional de Transporte Terrestre (ANTT); Flávia Alves - Agência Nacional de Telecomunicações (ANATEL); Fernanda Oliveira e Mariana Corrêa - Agência Nacional de Aviação Civil (ANAC) e Agência Nacional de Transportes Aquaviários (ANTAQ); Maria Luíza Troina e Mariana Toti - Agência Nacional de Energia Elétrica (ANEEL); Raphael Bruno Pesquisa teórica sobre comunicação pública e agências reguladoras.
} 
dizer que três hipóteses foram confirmadas: (i) a comunicação praticada pelas agências tende a estar enquadrada no paradigma da comunicação pública, ainda que falte um que fazer mais apropriado, uma práxis mais comprometida. Muito da comunicação praticada é institucional; (ii) o lócus da comunicação social dentro da estrutura das agências dificulta um trabalho integrado entre todas as áreas; e (iii) não há investimento em publicidade de utilidade pública que explique a razão da existência das agências faça a interação com o cidadão. Quanto à hipótese sobre a comunicação interna, os dados levantados permitem dizer que os funcionários estão integrados, porém, não permitem refutar ou confirmar a hipótese de que estão envolvidos com a missão, com a visão e com os valores da agência. Quanto ao discurso estratégico no campo dos media, os dados levantados indicam que essa hipótese está refutada, pois o Jornalismo praticado é de difusão de informação, ou seja, a prática está longe de um jornalismo público.

A jornalista Tatiany Tonelini em seu Estudo de Caso sobre a prática de Comunicação Pública no Mutirão da Cidadania da Secretaria de Justiça, Direitos Humanos e Cidadania do Distrito Federal (SEJUS), também aponta que a comunicação está muito mais para difusão do que para o incentivo ou a promoção da participação cidadã. O objetivo do Estudo de Caso foi verificar se a finalidade da comunicação é o interesse público, a transparência e o estímulo à participação popular e ao debate, aspectos essenciais para a construção da cidadania. O Estudo de Caso mostrou que não houve preocupação em estabelecer ações de estímulo ao debate e à participação do cidadão. As ações, concluiu a pesquisa, estão muito mais voltadas para a comunicação governamental - prestação de contas e engajamento da população nas ações propostas. O cidadão é apenas usuário do serviço, não participando da tomada de decisões sobre as políticas públicas adotadas. O mutirão foi realizado em abril de 2008, e, pelo Decreto 28.212, de 16 de agosto de 2007, a Secretaria tem por missão a promoção do pleno exercício da cidadania e da defesa dos direitos inalienáveis da pessoa humana.

As questões de Jornalismo Público são abordadas, no livro, em três artigos escritos por Vânia Ferreira, Lívia Davanzo e Lívia Almeida, respectivamente.

A jornalista Vânia traz a discussão sobre o arcabouço teórico do Jornalismo Público, mostrando que a fonte são pensadores, acadêmicos e jornalistas americanos e europeus. Aponta também que aos brasileiros coube ler e fazer referência a essas 
fontes e que a Campanha Paz no Trânsito em Brasília, na década de 90, desenvolvida pelo jornal Correio Braziliense é exemplo máximo da prática de jornalismo público.

Vânia questiona em seu artigo o motivo das repetições, da falta de estudos e de discussões sobre o jornalismo público na imensidão brasileira, e da falta de sistematização do que se está praticando. Ao lado de seus questionamentos, a jornalista incita as redações e os cursos de Comunicação a reverem os valores e os critérios de noticiabilidade para que o Jornalismo saia da repetição, do factual, do declaratório e do agendamento instantâneo para um Jornalismo que ajude a consolidar a cidadania e a participação do cidadão nas decisões políticas.

Vânia enfatiza que Jornalismo Público é parceria. E conclui dizendo que jornalismo público é a prática de um jornalismo associado ao enfrentamento de problemas e à promoção de condutas, mudanças de valores e atitudes para o avanço dos indivíduos como cidadãos; por isso é um incentivo para a sociedade e tem de ser uma prática permanente, uma vez que aponta caminhos, soluções e resultados.

A jornalista Lívia Davanzo fala das premissas e das práticas do jornalismo público na TV Brasil, criada pela Medida Provisória 398, que estabeleceu a rede pública de TV, e que tem a Empresa Brasil de Comunicação (EBC), criada no dia 11 de outubro de 2007, como gestora da TV Brasil. Após observar o processo de produção da notícia na TV Brasil, em Brasília, Lívia escreve que jornalismo público não combina com hard news, pois está muito mais para pautas que envolvam temas que possam ser tratados com profundidade, do que para pautas que tratem do factual. Apesar da vontade dos profissionais e da existência de indícios de jornalismo público na TV Brasil, esse tipo de jornalismo é visto como de segunda categoria. Para alterar essa ordem, é necessário que haja uma mudança nas práticas e nas rotinas produtivas. O próprio tempo para a produção de matérias de jornalismo público é diferente da correria do dia a dia, pois são matérias mais aprofundadas e, que, portanto, demandam mais tempo e dedicação.

Se Davanzo se preocupou em abordar a tevê pública, a jornalista Lívia Almeida se preocupou em pesquisar a prática de Jornalismo Público nas emissoras abertas de televisão. Cinco emissoras de TV comercial aberta em Brasília compõem o corpus do estudo: Balanço Geral e DF Record (Rede Record); Bom Dia DF e DFTV $1^{a}$ edição (Rede Globo) e Cidade Viva (SBT). Foram selecionados 10 quadros de espaço cidadão, 
exibidos no período de 9 a 14 de agosto de 2007 - Repórter Comunidade, Portal do Balanço e Balanço no Entorno (Balanço Geral); Assim não dá e Assim dá certo (DF Record); O microfone é seu, Mercado de Trabalho e Cesta do Bom Dia (Bom Dia DF); Olhar Cidadão (DFTV - $1^{\text {a }}$ edição) e Estúdio (Cidade Viva).

A conclusão do estudo aponta que há indícios de jornalismo público nos quadros estudados. No entanto, eles não são visíveis para os editores e produtores, que acabam considerando o jornalismo público como um jornalismo menor, uma vez que demonstram mais interesse por matérias factuais. Os editores e produtores tendem a utilizar critérios de audiência para a seleção do material, cedem pouco tempo para a veiculação do material noticioso, em comparação ao tempo total do telejornal, e valorizam a imagem e a dramaticidade dos fatos sociais. É possível inferir que nenhum dos quadros atende a todos os princípios do jornalismo público, principalmente no que diz respeito à legitimidade da comunicação, que ganha autenticidade quando o cidadão participa e acompanha a solução de problemas.

Para a edição do Prática de Comunicação Pública, Almeida atualizou a pesquisa e constata que, passados dez meses, o número de quadros de espaço cidadão foi reduzido pela metade. Os quadros Repórter Comunidade e Balanço no Entorno (Balanço Geral); Assim não dá e Assim dá certo (DF Record), da TV Record, saíram do ar. Na Rede Globo, o quadro Olhar Cidadão (DFTV - 1 a edição) também deixou de fazer parte da programação.

Diante disso, Lívia Almeida acredita que o telejornalismo brasileiro caminha para fusão com entretenimento e se distancia da função cidadã em um universo que valoriza, cada vez mais, a aparência sobre o conteúdo social das informações. Para ela, a prática de Jornalismo Público em tevês comerciais abertas tende a diminuir. Além disso, mostra-se pessimista com os rumos que a implantação da TV Digital vem tomando no país, a considerar o modelo aprovado que privilegia a alta definição de imagem e som em vez de multiplicidade de canais. Lívia entende que a transição, que poderia contribuir para a inclusão da sociedade no espaço público e munir o cidadão com informações para participar das decisões políticas e econômicas do país, pode diminuir ainda mais a participação cidadã nos meios de comunicação.

Campanhas educativas: publicidade de utilidade pública é pesquisa do Programa de Iniciação Científica (PIC - UniCEUB) do período 2008/2009. O objetivo 
é traçar vínculos entre Políticas Públicas e Publicidade Pública, de um lado, e de outro, a práxis do planejamento, da execução e da avaliação das campanhas públicas como ferramenta de suporte indispensável para o desenvolvimento de políticas públicas.

A leitura de coletânea@pública nos conduz às discrepâncias entre teoria e prática. As investigações científicas mostram que as práticas de assessorias de comunicação estão voltadas para prestação de contas mais do que para o engajamento do cidadão em participar de processos de decisão sobre políticas públicas que o envolvem. Além disso, os artigos demonstram que a lógica da audiência e o viés do info-entretenimento sobrepõem-se à lógica da informação jornalística. Jornalismo público requer uma prática noticiosa diferente e por isso é pouco compreendido pelos profissionais que o percebem como um jornalismo de segunda categoria.

\section{Abstract}

Práticas de Comunicação Pública em Brasília is the name of the book that gathers research work from seven journalists. The articles are about public television journalism and public media advise in Brasilia. The book was released on October $7^{\text {th }} 2008$, at the VI Education and Research Congress held by UniCEUB. The book was sponsored by the Diretório Central dos Estudantes and by the Entreposto Acadêmico. The articles talk about the practice of public communication inside of the Judiciary System, as well the principles of public education campaigns and how cable and commercial televisions aired public information. The book was organized by Mônica Prado, journalist and master in Communication, and the authors of the articles are: Aurilene Moura, Basilia Rodrigues, Lívia Almeida, Lívia Davanzo, Vânia Ferreira and Tatiany Tonelini.

Keywords: Public Communication, Citizenship, Education Campaigns.

\section{Referências}

PRADO, Mônica Igreja do (Org.). Coletânea@Pública: Práticas de comunicação pública em Brasília. Brasília: UniCeub, 2008. 